\title{
R\&M 2000 The Strategic Air Command Perspective
}

\author{
James P. McCarthy, Lieutenant General, USAF \\ Commander, Eighth Air Force \\ Strategic Air Command \\ (Former Deputy Chief of Staff, Plans Headquarters, \\ Strategic Air Command)
}

Key Words - Maintainability, Operational requirements, Design, Translation of requirements

\author{
Reader Aids - \\ Purpose: Explain the SAC R\&M initiatives \\ Special math needed for explanations: None \\ Special math needed to use results: None \\ Results useful to: Industry, planners, managers, engineers
}

\begin{abstract}
This paper discusses the force multiplier effects of $R \& M$ from an operating command perspective whose assets range from intercontinental ballistic missiles to complex command, control, and communication systems. When expressing a need for new systems, operational commands will state their requirements in operational terms which then must be translated into contractual terms. A new office has been formed to insure that clear requirements are formed. While forming requirements, specific attention must be given to the requirements for ease of maintenance. The manpower and materials implications of this up front planning are illustrated with the Minuteman III ICBM missile guidance set.
\end{abstract}

\section{INTRODUCTION}

SAC's motto - "Peace is our Profession" demands that it field systems with the highest possible reliability and maintainability (R\&M) in order to maintain a credible deterrent force. In addition to its primary mission of nuclear deterrence, SAC must be prepared to respond across the entire spectrum of conflict. To do that, the weapon systems - from high altitude supersonic reconnaissance aircraft, to cold-launched intercontinental ballistic missiles (ICBM), to mature fielded systems such as the B-52 bomber, the KC-135 air refueling tanker, and the Minuteman III ICBM - must be able to encounter and survive difficult operational environments. In addition to these front line weapon systems, SAC also operates a vast array of ground and orbital command, control and communication (C3) systems. The mission of deterrence requires great reliability that can be demonstrated on a dayto-day basis.

The Strategic Air Command (SAC) is totally committed to the goals and principles set forth by R\&M 2000. From its perspective, investments in better reliability and maintainability can directly improve SAC's readiness and combat capability. It needs systems that rarely break, and when they do, can be repaired quickly and easily. In this way, R\&M becomes a "force multiplier": increased combat capability using fewer resources. Obviously, increased emphasis on R\&M will pay increased dividends when they are designed into future systems, but they can also have the same benefit for fielded systems.

\section{REQUIREMENTS TRANSLATION}

Before R\&M can lead to improved combat capability, SAC must first adequately specify its operational requirements in parameters readily translatable into contractual terms for each of the five R\&M 2000 goals. A computer model is being developed to quantifiably link all operational measures of merit to all five R\&M goals. The resulting operational requirements will be used as the basis for system specifications to assure that SAC gets the system it needs. There must, however, be a consensus among the operating commands, the implementing commands, and the contractors as to which terms are to be used and how these terms are defined. Consequently, SAC supports the Scientific Advisory Board's efforts to recommend standardized R\&M terms that are meaningful and testable.

The competition for scarce resources, coupled with a rapidly changing threat, and the expense of redesigning system components make it increasingly difficult to field weapon systems which meet their required level of operational capability. However, proper R\&M planning throughout the design, test, and production phases will help insure that weapon systems delivered in the future are mature and supportable. Improved capabilities can be achieved when R\&M are considered from the inception of a new weapon system. SAC formed the new Directorate for Requirements Planning, centralizing the requirements planning process to make certain that $R \& M$ design criteria are clearly stated in requirements documents using standardized formats and testable performance standards. When engineers design a system with reliability and maintainability in mind, the result can be an effective increase in combat capability at little or no additional cost.

The use of 100 percent environmental stress screening (ESS) of applicable components is an essential tool to make systems reliable when delivered. Properly conducted ESS can also have a positive effect on the problem of spares provisioning for new weapon systems by eliminating defective parts before they reach operational status. That is to say, ESS identifies defective parts in the factory before they can cause critical failures in operational systems. With electronic boxes costing in the hundreds of thousands of dollars, SAC can ill afford to stockpile excessive spares to overcome poor 
reliability. ESS can help insure that systems put into service will give the required reliability and enable SAC to reduce its inventory of spare parts.

\section{THE M IN R\&M}

Often the emphasis is on the $\mathbf{R}$ of $\mathbf{R} \& \mathbf{M}$, but the $\mathbf{M}$ is equally important. A system can be very reliable, but if it is nearly impossible to fix when it does fail, the R\&M combination has failed. Improved R\&M can help achieve real manpower savings by decreasing the manhours needed to repair failed systems. However, like reliability, maintainability must be designed into a system up front to realize these savings. A good example of a piece of equipment designed with maintainability in mind is the drawerinsertable missile guidance set (MGS) on the Peacekeeper ICBM. Currently, to remove and replace the MGS on a Minuteman III ICBM, the silo closure door must be opened and the missile warhead removed. This operation requires three vehicles (a semi-truck and trailer, a five-ton support van, and a pickup truck), five maintenance personnel, and seven security policemen. With the new drawer-insertable unit, removing and replacing the Peacekeeper MGS does not require silo closure door opening or warhead removal. Therefore, on the Peacekeeper, this procedure requires only three maintenance personnel, one pickup truck, and one security policeman. The drawerinsertable MGS will result in substantially decreased life cycle costs for the Peacekeeper and demonstrates maintainability improvements attainable when a system is designed with both $\mathrm{R} \& \mathrm{M}$ in mind.

With the increasing complexity of weapon and C3 systems, one must also guard against increasing the complexity of their maintenance. The proliferation of special tools and support equipment for new systems must cease. To the extent possible, new systems must use existing tools and support equipment.
In addition to designing $R \& M$ into new systems, SAC must also concentrate on improving its fielded systems as they must last well into the next century. For these systems to continue to provide needed combat capability, they must be modernized to keep pace with increased threats and capabilities. It is important that these modifications be designed and fielded with R\&M in mind, as tremendous gains can be realized. For example, one component of the B-52 forward looking infrared radar system, the digital scan converter (DSC), was recently redesigned with R\&M being a key consideration. The new DSC was produced with a guaranteed mean time between failures (MTBF) of 4000 hours compared to the 260 hours MTBF experienced with the old DSC. In addition to increased reliability, the new DSC has the same form, fit, and function of the old DSC, costs 25 percent less, and requires only 2 percent of the 10-year life cycle costs of the old unit. While each weapon system upgrade obviously may not achieve the same startling results, increased combat capability, along with reduced manpower and costs, can be realized if proper emphasis is demanded on $\mathrm{R} \& \mathrm{M}$.

Designing new weapon and C3 systems, or modifying older ones, with R\&M in mind means that, upon system delivery, SAC can immediately fly the airplane, transmit the message, or put the missile on alert with confidence the system will work - or, if it fails, that downtime will be minimized. Increases in combat capability are possible through improvements in reliability and maintainability only if $R \& M$ are designed up front in new systems and are considered throughout the entire system life cycle. The Strategic Air Command needs improved R\&M today in order to have increased combat capability tomorrow.

Manuscript TR87-117 received 1986 December 5; revised 1987 April 20.

IEEE Log Number 15951 